\title{
PRODUTIVIDADE DO FEIJOEIRO EM RESPOSTA A ADUBAÇÃO FOSFATADA E A REGIMES DE IRRIGAÇÃO EM SOLO DE CERRADO1
}

\author{
LEO NOBRE DE MIRANDA², JUSCELINO ANTONIO DE AZEVEDO ${ }^{3}$, \\ JEANNE CHRISTINE CLAESSEN DE MIRANDA 4 E ANTONIO CARLOS GOMES ${ }^{5}$
}

\begin{abstract}
RESUMO - O cultivo do feijoeiro (Phaseolus vulgaris L.) irrigado nos solos de cerrado requer a utilização de fertilizantes fosfatados. Este trabalho foi desenvolvido com o objetivo de estudar o efeito do manejo da adubação fosfatada e da lâmina de água na produtividade do feijoeiro em Latossolo VermelhoEscuro argiloso. Os tratamentos englobaram três doses de adubação fosfatada a lanço $(250,500$ e $1.000 \mathrm{~kg} \mathrm{ha}^{-1}$ de $\mathrm{P}_{2} \mathrm{O}_{5}$ ) e dois níveis de irrigação (adequado e restrito), determinados em função de tensões de água no solo. Foi cultivado o feijão 'Carioca' (quatro cultivos) no período seco, em rotação com o milho 'BR 201' (cinco cultivos), no período chuvoso. A produção de grãos do feijão aumentou com a adubação fosfatada, nos dois níveis de irrigação, sendo maior com a dose mais alta de adubação e irrigação adequada. A irrigação restrita promoveu reduções de produtividade em todos os tratamentos, sendo menos prejudicial no solo com maior disponibilidade de P. O milho apresentou também resposta significativa à adubação fosfatada, e o efeito residual dessa adubação manteve boas produtividades das duas culturas durante os vários cultivos sucessivos.
\end{abstract}

Termos para indexação: Phaseolus vulgaris, feijão, milho, fósforo, efeito residual de fósforo.

\section{PRODUCTIVITY OF COMMON BEAN IN RELATION TO PHOSPHATE FERTILIZER AND IRRIGATION IN A CERRADO SOIL}

\begin{abstract}
The cultivation of common bean (Phaseolus vulgaris L.) with irrigation in cerrado soils, requires the application of phosphate fertilizers. A field experiment was carried out to study the effect of phosphate and water levels on the common bean grain yield in a clay Dark-Red Latosol. Treatments consisted of three levels of phosphate fertilizer $\left(250,500\right.$ and $1.000 \mathrm{~kg} \mathrm{ha}^{-1}$ of $\left.\mathrm{P}_{2} \mathrm{O}_{5}\right)$ and two water levels (adequate and restricted), defined according to the water tension in the soil. It was cultivated the common bean cultivar Carioca (four crops) in the dry season, in rotation with corn cultivar BR 201 (five crops) in the rainy season. The common bean grain yield increased with phosphate levels in both water levels, being higher with the higher phosphate level and adequate irrigation. Restricted irrigation promoted a general decreasing in grain yield but with less intensity in the soil with higher phosphate availability. Corn grain yield also increased with the phosphate levels. The phosphate residual effects maintained a good grain production for both crops throughout the various years of cropping.
\end{abstract}

Index terms: Phaseolus vulgaris, corn, phosphorus, phosphate residual effect.

\section{INTRODUÇ̃̃O}

O cultivo do feijoeiro irrigado nos solos de cerrado requer a aplicação e a utilização eficiente de

\footnotetext{
${ }^{1}$ Aceito para publicação em 2 de junho de 1999.

${ }^{2}$ Eng. Agrôn., Ph.D., Embrapa-Centro de Pesquisa Agropecuária dos Cerrados (CPAC), Caixa Postal 08223 CEP 73301-970 Planaltina, DF. E-mail: leo@cpac.embrapa.br ${ }^{3}$ Eng. Agrôn., Dr., Embrapa-CPAC.

${ }^{4}$ Bióloga, Ph.D., Embrapa-CPAC

${ }^{5}$ Matemático, Ph.D., Embrapa-CPAC.
}

fertilizantes, para elevar a fertilidade do solo e a produtividade. Sobre alguns fertilizantes, como nitrogenados e potássicos, existem dados disponíveis sobre a dinâmica e eficiência na produtividade das culturas, em condições irrigadas (Hagin \& Tucker, 1982; James et al., 1982). Entretanto, para o fertilizante fosfatado, existem poucas informações quanto à eficiência em sistemas irrigados intensivos. O P é um elemento pouco móvel no solo e seu suprimento para as raízes é efetuado principalmente pelo processo de difusão, o qual depende da umidade do solo e da superfície radicular (Olsen 
\& Watanabe, 1970; Barber, 1974; Gahoonia et al., 1994). Por sua vez, a umidade do solo interfere diretamente no desenvolvimento das raízes (MacKay \& Barber, 1985) influenciando, então, de forma direta e indireta, no fornecimento de $\mathrm{P}$ para as plantas.

Para algumas espécies como trigo e cevada (Ignazi, 1977), lentilha e trigo (Matar, 1977) e soja (Ruiz et al., 1988), têm sido observadas maiores respostas à adubação fosfatada, em condições de estresse hídrico, pois este afeta o desenvolvimento das plantas, de forma mais drástica, nos solos com teores baixos de P disponível (Ignazi, 1977; Matar, 1977). O feijoeiro tem apresentado, também, respostas significativas à adubação fosfatada (Barbosa Filho \& Silva, 1994; Stone \& Pereira, 1994; Carvalho et al., 1995); a lâmina de água aplicada e o turno de rega podem afetar a produtividade de grãos dessa cultura (Silveira et al., 1984). Os dados da literatura indicam que o manejo da irrigação pode interferir de forma significativa na eficiência da adubação fosfatada. Frizzone et al. (1982) e Silveira \& Moreira (1990) mostram que um mesmo rendimento de grãos do feijoeiro irrigado pode ser obtido com diferentes combinações de doses de P e lâminas de água. Esses autores mostram, ainda, que a eficiência de uso do adubo fosfatado pelo feijoeiro foi maior com o aumento da disponibilidade de água.

Este trabalho teve o objetivo de estudar o efeito do manejo da irrigação e da adubação fosfatada na produtividade do feijoeiro, em solo de cerrado.

\section{MATERIAL E MÉTODOS}

O experimento foi implantado em 1990 na EmbrapaCentro de Pesquisa Agropecuária dos Cerrados (CPAC), Planaltina, DF, em Latossolo Vermelho-Escuro argiloso. As características iniciais do solo foram: $\mathrm{pH}$ em água $(1: 2,5)=5,3 ; 0,85 \mathrm{cmol}_{\mathrm{c}} \mathrm{dm}^{-3} \mathrm{de} \mathrm{Al}^{3+} ; 0,03 \mathrm{cmol}_{\mathrm{c}} \mathrm{dm}^{-3} \mathrm{de}$ $\mathrm{K}^{+} ; 0,70 \mathrm{cmol}_{\mathrm{c}} \mathrm{dm}^{-3}$ de $\mathrm{Ca}^{2+}+\mathrm{Mg}^{2+} ; 6,81 \mathrm{cmol}_{\mathrm{c}} \mathrm{dm}^{-3} \mathrm{de}$ $\mathrm{H}^{+}+\mathrm{Al}^{3+} ; 9,7 \%$ de saturação por bases (V); $24 \mathrm{~g} \mathrm{dm}^{-3} \mathrm{de} \mathrm{C}$; $1,1 \mathrm{mg} \mathrm{dm}^{-3} \mathrm{de} \mathrm{P} ; 530 \mathrm{~g} \mathrm{dm}^{-3}$ de argila; $70 \mathrm{~g} \mathrm{dm}^{-3}$ de silte $\mathrm{e}$ $400 \mathrm{~g} \mathrm{dm}^{-3}$ de areia.

Os tratamentos utilizados consistiram da combinação de três doses de adubação fosfatada a lanço: 250 (P1), 500 (P2) e 1.000 (P3) kg ha-1 de $\mathrm{P}_{2} \mathrm{O}_{5}$, como superfosfato triplo, e dois níveis de irrigação: adequado (IA) e restrito (IR), determinados em função de tensões de água no solo, fixas e diferenciadas, ao longo do ciclo da cultura do feijão no período seco, conforme descritos na Tabela 1. A partir do terceiro cultivo de feijão, em 1993, foram adotadas tensões fixas de água no solo durante todo o ciclo da cultura. Utilizou-se o delineamento de blocos ao acaso, em esquema fatorial, com três repetições, em quatro cultivos. Como tratamento adicional foi incluído um terceiro nível de irrigação, usual (IU) na região, em que a lâmina de água foi calculada com base na evaporação do tanque classe $\mathrm{A}$, combinado apenas com a dose de $\mathrm{P} 2$ de $\mathrm{P}$, que era o nível de adubação onde se esperava a máxima produtividade das culturas. As informações obtidas neste tratamento se completaram no terceiro ano, e antes do quarto cultivo de feijão, o tratamento foi modificado, aplicando-se o nível de irrigação adequado e uma adubação fosfatada a lanço, de $900 \mathrm{~kg} \mathrm{ha}^{-1}$ de $\mathrm{P}_{2} \mathrm{O}_{5}$, para confirmação dos dados observados de resposta linear do feijão a altos níveis de adubação fosfatada a lanço.

Foi plantado o feijão, cultivar Carioca, no período seco, com densidade de plantio de 200.000 plantas ha-1 e espaçamento entre linhas de $0,50 \mathrm{~m}$. Os tratamentos foram instalados em parcelas de $12 \mathrm{~m}$ x $12 \mathrm{~m}$, separadas por corredores de $6 \mathrm{~m}$ de comprimento para evitar superposições de água das diferentes parcelas irrigadas. Para a irrigação, foram instalados quatro aspersores do tipo setorial por parcela, colocando-se um em cada canto da parcela. No período chuvoso foi cultivado o milho, cultivar BR 201, como cultura de rotação, com densidade de plantio de 50.000 plantas ha ${ }^{-1}$ e espaçamento entre linhas de $1,00 \mathrm{~m}$. Para análise estatística dos dados do milho, não foram considerados os tratamentos de irrigação, tendo-se, então, três doses de adubação fosfatada e seis repetições, em cinco cultivos.

Antes de cada plantio foram coletadas amostras de solo em cada parcela, compostas de 20 subamostras e na profundidade de 0 a $20 \mathrm{~cm}$, para análise química de acordo com os métodos da Embrapa (1979). Foram realizadas amostragens de folhas do feijão e do milho no florescimento, bem como de grãos após a colheita, para análise química dos teores de macros e micronutrientes.

O trabalho experimental foi iniciado em abril de 1990, com a aplicação de 5,0 t ha ${ }^{-1}$ de calcário dolomítico, para elevar a saturação por bases do solo para $60 \%$, incorporado com arado na profundidade de $20 \mathrm{~cm}$. Fez-se, então, um ensaio em branco com a cultura do milho para identificar possíveis desuniformidades na área e evitá-las. No início do período chuvoso, outubro de 1990, aplicaram-se, a lanço, as doses de adubação fosfatada como superfosfato triplo, incluindo-se também $\mathrm{K}$ na dose de $180 \mathrm{~kg} \mathrm{ha}^{-1}$ de $\mathrm{K}_{2} \mathrm{O}$, como cloreto de potássio; micronutrientes, com a dose de $60 \mathrm{~kg} \mathrm{ha}^{-1}$ de FTE BR-12 e $1.500 \mathrm{~kg} \mathrm{ha}^{-1}$ de gesso, incorporados com 
grade aradora. No ano agrícola 1990/91 foi iniciado o experimento com o cultivo do milho, que recebeu uma adubação nitrogenada de $120 \mathrm{~kg} \mathrm{ha}^{-1}$ de $\mathrm{N}$ na forma de uréia, sendo $1 / 3$ no plantio, $1 / 3 \mathrm{em}$ cobertura aos 35 dias, e $1 / 3$ aos 45 dias. No início do período seco de 1991 foram implantados os tratamentos de irrigação, plantando-se o feijão na primeira quinzena do mês de junho de 1991. Essa cultura recebeu também uma adubação nitrogenada de $80 \mathrm{~kg} \mathrm{ha}^{-1}$ de $\mathrm{N}$ na forma de uréia, sendo 1/3 no plantio, 1/3 em cobertura aos 20 dias, e 1/3 aos 35 dias. As sementes foram ainda infectadas com Rhizobium leguminosarum bv. phaseoli, antes do plantio, com a dose de $1 \mathrm{~kg}$ de inoculante por $40 \mathrm{~kg}$ de sementes. Nos cultivos seguintes de milho e feijão foi mantida a mesma adubação nitrogenada e aplicada uma adubação de manutenção de K para cada cultura, de acordo com a análise do solo, e a inoculação foi feita para o feijão.

Os dados obtidos foram submetidos à análise de variância e as médias comparadas pelo teste de Tukey a $5 \%$ de probabilidade.

\section{RESULTADOS E DISCUSSÃO}

\section{Produtividade de grãos}

A lâmina média de água, aplicada nos quatro cultivos, foi de 426 e $338 \mathrm{~mm}$ por ciclo respectivamente para IA e IR, e os dados de produtividade dos quatro cultivos de feijão em função dos níveis de água e de P são mostrados na Tabela 2. Observa-se que as produtividades aumentaram com a adubação fosfatada tanto no tratamento adequado de irrigação quanto no restrito. Obtiveram-se, em geral, produtividades maiores no tratamento IAP3, que com- bina o nível mais alto de adubação fosfatada e condições adequadas de água. A irrigação restrita promoveu reduções de produtividade em todos os tratamentos de adubação. Entretanto, observa-se que as produtividades do tratamento IRP 3 foram semelhantes às do tratamento IAP2 no primeiro cultivo e significativamente superiores nos cultivos seguintes e na produção total, indicando um menor efeito negativo do regime restrito de irrigação, no solo com maior disponibilidade de P. No tratamento adicional IUP2 foi aplicada, nos três primeiros cultivos, uma lâmina média de $486 \mathrm{~mm}$ por ciclo, obtendose produção de grãos próxima à obtida no tratamento IAP2, com a mesma adubação fosfatada, embora tenha recebido uma lâmina de água maior.

No cultivo de 1994, observou-se um decréscimo geral da produtividade do feijão em relação ao ano anterior, devido, provavelmente, à perda do efeito residual do adubo fosfatado aplicado a lanço no início do experimento. Esses dados indicam a necessidade de reposição de $\mathrm{P}$, o que se pode observar no tratamento IUP2, onde foram aplicados $900 \mathrm{~kg} \mathrm{ha}^{-1}$ de $\mathrm{P}_{2} \mathrm{O}_{5}$ a lanço no quarto cultivo, obtendo-se produtividade média de $3.736 \mathrm{~kg} \mathrm{ha}^{-1}$. Esse resultado evidencia novamente a resposta significativa do feijão a altos níveis de adubação fosfatada aplicados a lanço antes do plantio. Outros autores têm observado uma resposta acentuada em rendimento de grãos do feijão, devido tanto ao efeito das lâminas de irrigação quanto ao da adubação fosfatada no sulco de plantio (Silveira \& Moreira, 1990). Frizzone et al. (1982) observaram aumentos de produtividade do feijoeiro em resposta

TABELA 1. Tratamentos de irrigação, em função da tensão de água no solo no momento da irrigação do feijão, nos estádios vegetativo (V), floração/formação vagens (F/V) e maturação (M) e, profundidade de controle dos tratamentos ${ }^{1}$.

\begin{tabular}{lcccc}
\hline Irrigação $^{2}$ & \multicolumn{3}{c}{ Tensão de água no solo (MPa) } & Profundidade \\
\cline { 2 - 4 } & $\mathrm{V}$ & $\mathrm{F} / \mathrm{V}$ & $\mathrm{M}$ & $(\mathrm{cm})$ \\
\hline Adequado (IA) & $0,10(0,04)$ & $0,03(0,04)$ & $0,05(0,04)$ & 10 \\
Restrito (IR) & $0,30(0,50)$ & $0,06(0,50)$ & $0,07(0,50)$ & $15(10)$ \\
Usual (IU) & 0,10 & 0,10 & 0,10 & 10 \\
\hline
\end{tabular}

1 Valores entre parênteses estabelecidos a partir do terceiro cultivo em 1993.

2 Irrigações calculadas com base na deficiência hídrica até $35 \mathrm{~cm}$ de profundidade, avaliada por tensiômetros e blocos de gesso (IA e IR) e por evaporação do tanque Classe A (IU). 
à aplicação crescente de $\mathrm{P}$, no solo irrigado com as lâminas de água entre 350 a $485 \mathrm{~mm}$ por ciclo.

A interação entre os tratamentos de água e de fósforo foi estatisticamente significativa $(p<0,05)$, podendo-se observar em todos os cultivos que a produtividade de grãos no tratamento IAP3 foi sempre superior aos demais tratamentos. Os dados de produtividade para os níveis de irrigação, independentemente das doses de adubação fosfatada e viceversa (Tabela 3), mostram que para o feijão com irrigação adequada, a produtividade foi significativamente maior que com a irrigação restrita. $\mathrm{Na}$ média dos quatro cultivos (Fig. 1), tal comportamento está bem evidenciado, com menor produtividade para IR, em todas as doses de P. Ruiz et al. (1988) observaram também, em casa de vegetação, uma diminuição nos parâmetros de crescimento da soja, com a redução do potencial matricial, em todos os níveis de adubação fosfatada, sendo esse efeito mais marcante no solo mais arenoso, com menor capacidade de retenção de água.

Para o milho cultivado nos períodos chuvosos, obteve-se uma resposta significativa à adubação fosfatada (Tabela 4). Na dose de $250 \mathrm{~kg} \mathrm{ha}^{-1}$ de $\mathrm{P}_{2} \mathrm{O}_{5}$, a maior produtividade foi obtida no primeiro cultivo. Na adubação de $500 \mathrm{~kg} \mathrm{ha}^{-1}$ de $\mathrm{P}_{2} \mathrm{O}_{5}$, a produtividade foi semelhante no primeiro e segundo cultivos, e maior no terceiro cultivo, decrescendo no quarto e quinto cultivos. A produção de grãos na dose mais alta de $\mathrm{P}_{2} \mathrm{O}_{5}$, exceto no primeiro cultivo, foi sempre superior às demais e crescente até 0 quarto cultivo. Miranda et al. (1980), em trabalho realizado no mesmo solo de cerrado, obtiveram produtividades de milho semelhantes às obtidas neste experimento, em resposta a doses de adubação fosfatada a lanço, ocorrendo também boas produtividades ao longo dos anos, principalmente nas doses mais altas de P.

\section{Efeito residual da adubação fosfatada}

As doses de adubo fosfatado aplicadas a lanço antes do primeiro plantio apresentaram um efeito residual, pelos cultivos sucessivos de feijão e milho, que se refletiu na manutenção de boas produtividades das duas culturas. Esse aspecto é importante para o manejo da adubação fosfatada e deve ser considerado na definição das doses de adubação a serem utilizadas nos sistemas de produção. A produtividade das culturas, em geral, foi diminuindo com o tempo, provavelmente, em conseqüência da

TABELA 2. Produtividade de grãos de feijão, cultivar Carioca, em função de níveis de irrigação e de doses de $\mathrm{P}_{2} \mathrm{O}_{5}$ em Latossolo Vermelho-Escuro. Dados médios de três repetições ${ }^{1}$.

\begin{tabular}{lcccccc}
\hline Tratamento $^{2}$ & \multicolumn{7}{c}{ Produtividade } \\
\cline { 2 - 6 } & 1991 & 1992 & 1993 & 1994 & Total & Média \\
\hline & $-1.925 \mathrm{~b}$ & $1.060 \mathrm{~d}$ & $920 \mathrm{e}$ & $237 \mathrm{e}$ & $4.142 \mathrm{~d}$ & $1.036 \mathrm{~d}$ \\
IAP1 & $2.183 \mathrm{~b}$ & $1.887 \mathrm{c}$ & $1.946 \mathrm{c}$ & $812 \mathrm{c}$ & $6.828 \mathrm{c}$ & $1.707 \mathrm{c}$ \\
IAP2 & $3.191 \mathrm{a}$ & $3.085 \mathrm{a}$ & $3.718 \mathrm{a}$ & $2.211 \mathrm{a}$ & $12.205 \mathrm{a}$ & $3.051 \mathrm{a}$ \\
IAP3 & $1.494 \mathrm{c}$ & $1.004 \mathrm{~d}$ & $847 \mathrm{e}$ & $182 \mathrm{a}$ & $3.528 \mathrm{~d}$ & $882 \mathrm{~d}$ \\
IRP1 & $1.923 \mathrm{~b}$ & $1.756 \mathrm{c}$ & $1.703 \mathrm{~d}$ & $575 \mathrm{~d}$ & $5.956 \mathrm{c}$ & $1.489 \mathrm{c}$ \\
IRP2 & $2.383 \mathrm{~b}$ & $2.827 \mathrm{~b}$ & $2.602 \mathrm{~b}$ & $1.939 \mathrm{~b}$ & $9.750 \mathrm{~b}$ & $2.438 \mathrm{~b}$ \\
IRP3 & 2.225 & 2.099 & 2.147 & 3.736 & - & - \\
IUP2 & 10,4 & 6,1 & 5,3 & 10,8 & 6,9 & 7,2 \\
\hline CV $(\%)$ & & & & & & \\
\hline
\end{tabular}

1 Valores seguidos da mesma letra, em cada coluna, não diferem estatisticamente pelo teste de Tukey a $5 \%$ de probabilidade.

2 IA: irrigação adequada; IR: irrigação restrita; IU: irrigação usual; $\mathrm{P} 1: 250 \mathrm{~kg} \mathrm{ha}^{-1} \mathrm{de}_{2} \mathrm{O}_{5} ; \mathrm{P} 2: 500 \mathrm{~kg} \mathrm{ha}^{-1} \mathrm{de}_{2} \mathrm{O}_{5} ; \mathrm{P}_{3}: 1.000 \mathrm{~kg} \mathrm{ha}^{-1}$ de $\mathrm{P}_{2} \mathrm{O}_{5}$; IUP2: tratamento adicional não considerado na análise estatística. 
TABELA 3. Produtividade média de grãos de feijão, cultivar Carioca, em Latossolo Vermelho-Escuro, em razão de níveis de irrigação (I) e de doses de $\mathrm{P}_{2} \mathrm{O}_{5}(\mathrm{P})^{1}$.

\begin{tabular}{|c|c|c|c|c|c|}
\hline \multirow[t]{2}{*}{ Tratamento } & \multicolumn{5}{|c|}{ Produtividade } \\
\hline & 1991 & 1992 & 1993 & 1994 & Média \\
\hline & \multicolumn{5}{|c|}{ - } \\
\hline IA & $2.433 \mathrm{aA}$ & $2.011 \mathrm{aC}$ & $2.194 \mathrm{aB}$ & $1.087 \mathrm{aD}$ & $1.931 \mathrm{a}$ \\
\hline IR & $1.933 \mathrm{bA}$ & $1.862 \mathrm{aA}$ & $1.717 \mathrm{bB}$ & $899 \mathrm{aC}$ & $1.603 \mathrm{~b}$ \\
\hline CV (\%) & & & & & 6,2 \\
\hline $\mathrm{P} 1$ & $1.710 \mathrm{cA}$ & $1.032 \mathrm{cB}$ & $883 \mathrm{cB}$ & $210 \mathrm{cC}$ & $959 c$ \\
\hline $\mathrm{P} 2$ & $2.053 \mathrm{bA}$ & $1.821 \mathrm{bB}$ & $1.824 \mathrm{bB}$ & $693 \mathrm{bC}$ & $1.598 \mathrm{~b}$ \\
\hline P3 & $2.787 \mathrm{aC}$ & $2.956 \mathrm{aB}$ & $3.160 \mathrm{aA}$ & $2.074 \mathrm{aD}$ & $2.744 \mathrm{a}$ \\
\hline CV (\%) & & & & & 5,9 \\
\hline
\end{tabular}

${ }_{1}^{1}$ Para I e P individualmente, as médias seguidas da mesma letra, minúscula em cada coluna e maiúscula em cada linha, não diferem estatisticamente pelo teste de Tukey a $5 \%$ de probabilidade.

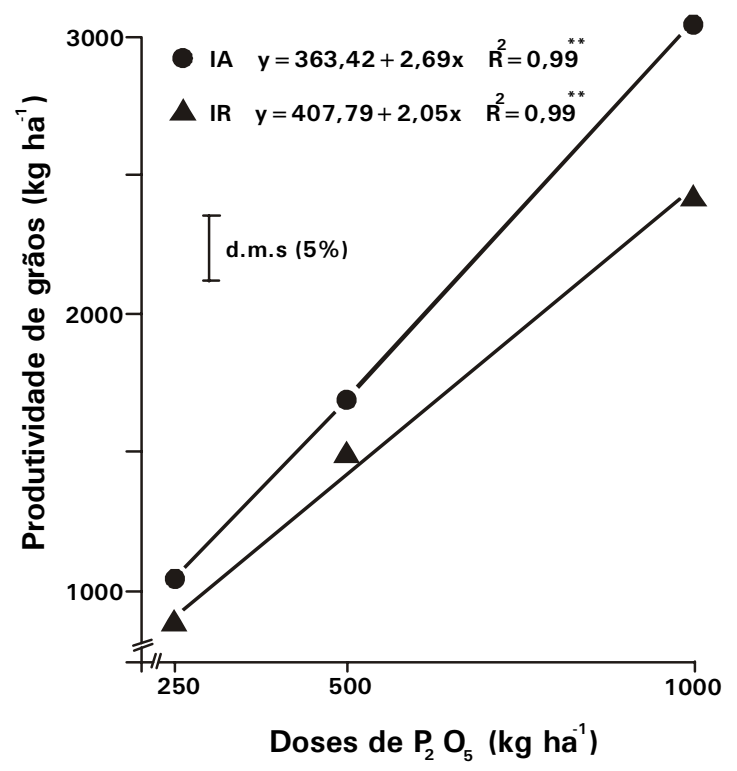

FIG. 1. Produtividade média de grãos de quatro cultivos de feijão, cultivar Carioca, em Latossolo Vermelho-Escuro argiloso de cerrado, em condições adequadas (IA) e restritas (IR) de irrigação.

perda do efeito residual do adubo aplicado a lanço antes do primeiro cultivo. Pode-se observar um decréscimo gradativo de produtividade do feijão, principalmente nas doses de $\mathrm{P}_{2} \mathrm{O}_{5}$ mais baixas (Ta- bela 3). Na dose P3, houve um acréscimo de produtividade até o terceiro cultivo de feijão, com uma redução significativa no quarto cultivo, em 1994. No milho (Tabela 4), o decréscimo desse efeito residual só foi observado para a dose de $250 \mathrm{~kg} \mathrm{ha}^{-1}$ de $\mathrm{P}_{2} \mathrm{O}_{5}$ a partir do quarto cultivo, e para a dose de $500 \mathrm{~kg} \mathrm{ha}^{-1}$ de $\mathrm{P}_{2} \mathrm{O}_{5}$ no quinto cultivo. Miranda \& Lobato (1978) observaram também a resposta acentuada de cinco cultivares de feijão, ao efeito residual da adubação fosfatada a lanço, em doses semelhantes às aplicadas neste experimento, ocorrendo, entretanto, uma variabilidade de comportamento entre as cultivares.

As características químicas do solo antes do primeiro plantio de feijão e antes do quinto plantio de milho são apresentadas na Tabela 5. Pode-se observar que os teores de $\mathrm{P}$ disponível no solo decresceram com o tempo de cultivo e que após quatro cultivos de feijão e quatro de milho, a dose de $1.000 \mathrm{~kg} \mathrm{ha}^{-1}$ de $\mathrm{P}_{2} \mathrm{O}_{5}$ ainda mantinha teores no solo de $15,7 \mathrm{mg} \mathrm{dm}^{-3}$ de $\mathrm{P}$, acima do nível considerado crítico para culturas anuais nesse solo (Miranda et al., 1980).

O feijão apresentou, em média, para os quatro cultivos com irrigação adequada, as produtividades de $1.036,1.707$ e $3.051 \mathrm{~kg} \mathrm{ha}^{-1}$, respectivamente para as doses de 250,500 e $1.000 \mathrm{~kg} \mathrm{ha}^{-1}$ de $\mathrm{P}_{2} \mathrm{O}_{5}$. A resposta da cultura à adubação foi linear até a dose mais alta de $1.000 \mathrm{~kg} \mathrm{ha}^{-1}$ de $\mathrm{P}_{2} \mathrm{O}_{5}$, a lanço. Nessas 
TABELA4. Produtividade média de cinco cultivos de milho, cultivar BR-201, em função de doses de P aplicadas a lanço antes do primeiro plantio em Latossolo Vermelho-Escuro. Dados médios de seis repetições ${ }^{1}$.

\begin{tabular}{|c|c|c|c|c|c|c|}
\hline \multirow[t]{2}{*}{ Tratamento $^{2}$} & \multicolumn{6}{|c|}{ Produtividade } \\
\hline & 1990/91 & $1991 / 92$ & $1992 / 93$ & 1993/94 & $1994 / 95$ & Média \\
\hline & \multicolumn{6}{|c|}{ - } \\
\hline $\mathrm{P} 1$ & $5.679 \mathrm{bA}$ & $5.164 \mathrm{cA}$ & $5.475 \mathrm{cA}$ & $3.616 \mathrm{cB}$ & $1.954 \mathrm{cC}$ & $4.378 \mathrm{c}$ \\
\hline $\mathrm{P} 2$ & $6.414 \mathrm{aB}$ & $6.258 \mathrm{bB}$ & $7.519 \mathrm{bA}$ & $6.257 \mathrm{bB}$ & $4.047 \mathrm{bC}$ & $6.099 \mathrm{~b}$ \\
\hline P3 & $6.522 \mathrm{aC}$ & $7.265 \mathrm{aB}$ & $8.767 \mathrm{aA}$ & $8.961 \mathrm{aA}$ & $6.746 \mathrm{aBC}$ & $7.652 \mathrm{a}$ \\
\hline
\end{tabular}

${ }^{1}$ Médias seguidas da mesma letra, minúscula em cada coluna e maíuscula em cada linha, não diferem estatisticamente pelo teste de Tukey a $5 \%$ de probabilidade; $\mathrm{CV}$ Ano $* \mathrm{P}=7,3 \%$.

2 P1: $250 \mathrm{~kg} \mathrm{ha}^{-1}$ de $\mathrm{P}_{2} \mathrm{O}_{5}$; P2: $500 \mathrm{~kg} \mathrm{ha}^{-1}$ de $\mathrm{P}_{2} \mathrm{O}_{5}$; $\mathrm{P} 3$ : $1.000 \mathrm{~kg} \mathrm{ha}^{-1}$ de $\mathrm{P}_{2} \mathrm{O}_{5}$.

TABELA 5. Características químicas do solo antes do 10 plantio de feijão e antes do 5o plantio de milho. Teores de $P$ nas três doses de adubação fosfatada (P1, P2, P3).

\begin{tabular}{lcc}
\hline Características do solo & $\begin{array}{c}\text { Março } \\
1991\end{array}$ & $\begin{array}{c}\text { Outubro } \\
1994\end{array}$ \\
\hline $\mathrm{pH}$ em água $(1: 2,5)$ & 5,8 & 5,4 \\
$\mathrm{Al}^{3+}\left(\mathrm{cmol}_{\mathrm{c}} \mathrm{dm}^{-3}\right)$ & 0,1 & 0,1 \\
$\mathrm{Ca}^{2+}+\mathrm{Mg}^{2+}\left(\mathrm{cmol}_{\mathrm{c}} \mathrm{dm}^{-3}\right)$ & 3,5 & 3,9 \\
$\mathrm{~K}^{+}\left(\mathrm{cmol}_{\mathrm{c}} \mathrm{dm}^{-3}\right)$ & 0,1 & 2,3 \\
$\mathrm{H}^{+}+\mathrm{Al}^{+}\left(\mathrm{cmol}_{\mathrm{c}} \mathrm{dm}^{-3}\right)$ & 4,5 & 5,8 \\
$\mathrm{Sat}_{\mathrm{bases}(\%)}$ & 44,0 & 41,0 \\
$\mathrm{C}\left(\mathrm{g} \mathrm{dm}^{-3}\right)$ & 22,0 & 23,0 \\
$\mathrm{P} 1\left(\mathrm{mg} \mathrm{dm}^{-3}\right)$ & 9,8 & 3,9 \\
$\mathrm{P} 2\left(\mathrm{mg} \mathrm{dm}^{-3}\right)$ & 21,6 & 6,4 \\
$\mathrm{P} 3\left(\mathrm{mg} \mathrm{dm}^{-3}\right)$ & 49,4 & 15,7 \\
\hline
\end{tabular}

mesmas doses de adubação fosfatada, a produtividade do milho foi, como média dos cinco cultivos, respectivamente, equivalente a 4,2, 3,6 e 2,5 vezes a produtividade do feijão nas mesmas doses de adubação fosfatada. $\mathrm{O}$ maior acréscimo de produtividade foi obtido até a dose de $500 \mathrm{~kg} \mathrm{ha}^{-1}$ de $\mathrm{P}_{2} \mathrm{O}_{5}$. Essa diferença de resposta à adubação fosfatada entre as duas culturas pode estar relacionada às diferenças na eficiência de absorção de nutrientes do solo, em função da própria estrutura do sistema radicular das plantas. O feijão tem um sistema radicular pouco desenvolvido e explora um pequeno volume de solo (Inforzato \& Myasaka, 1963; Rosolem, 1987), que se refletiria no menor apro- veitamento do $\mathrm{P}$ aplicado a lanço e disponível em toda a camada arável.

Comparando os dados obtidos com os de outros autores (Berger et al., 1982; Silveira \& Moreira, 1990; Barbosa Filho \& Silva, 1994), pode-se deduzir que a adubação fosfatada para o feijoeiro seria mais eficiente se aplicada de forma concentrada, pois produtividades semelhantes às deste trabalho foram obtidas pelos referidos autores, com doses bem menores de $\mathrm{P}_{2} \mathrm{O}_{5}$ aplicadas no sulco de plantio. Por sua vez, as diferenças no desenvolvimento da cultura do milho, causadas pela forma de aplicação da adubação fosfatada, não seriam tão significativas, em virtude do tamanho do sistema radicular e da distribuição em maior volume de solo. Model \& Anghinoni (1992) obtiveram, praticamente, a mesma produtividade para o milho em relação à adubação fosfatada aplicada a lanço, em faixa ou no sulco, e as diferenças no crescimento das plantas em decorrência dessas formas de aplicação do adubo só ocorreram na fase inicial de crescimento das plantas.

Os teores médios de nutrientes nas folhas e grãos de feijão e de milho dos quatro primeiros cultivos são apresentados na Tabela 6. Para o feijão com irrigação restrita, houve uma tendência de menores teores foliares de $\mathrm{P}$ em todos os tratamentos de adubação fosfatada. De modo geral, os teores de macro e micronutrientes nas folhas do feijão e do milho estão próximos ou ligeiramente superiores àqueles considerados críticos para essas duas culturas (Raij, 1991). 
TABELA 6. Teores médios de nutrientes, nas folhas e grãos de feijão, em dois níveis de irrigação (IA, IR) e de milho. Dados médios de quatro cultivos ${ }^{1}$.

\begin{tabular}{|c|c|c|c|c|c|c|c|c|c|c|c|c|c|}
\hline Planta $^{2}$ & $\mathrm{P}_{1}$ & $\mathrm{P}_{2}$ & $\mathrm{P}_{3}$ & $\mathrm{~N}$ & $\mathrm{~K}$ & $\mathrm{Ca}$ & $\mathrm{Mg}$ & $\mathrm{S}$ & $\mathrm{Zn}$ & $\mathrm{Cu}$ & $\mathrm{Fe}$ & $\mathrm{Mn}$ & B \\
\hline & --- & -.. & -- & -( & -1 & -- & 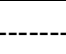 & ---- & ----- & -- & $(\mathrm{mg} \mathrm{k}$ & 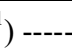 & \\
\hline \multicolumn{14}{|l|}{ Feijão } \\
\hline Folha - IA & 2,8 & 3,1 & 3,8 & 42 & 20 & 18 & 5,0 & 1,5 & 31 & 6,5 & 459 & 34 & 61 \\
\hline Folha - IR & 2,7 & 2,9 & 3,4 & 41 & 18 & 18 & 5,2 & 1,3 & 32 & 6,6 & 454 & 36 & 61 \\
\hline Grão - IA & 3,0 & 3,0 & 3,3 & 30 & 10 & 4 & 2,4 & 1,2 & 30 & 6,2 & 196 & 11 & 22 \\
\hline Grão - IR & 3,0 & 3,0 & 3,3 & 31 & 10 & 4 & 2,4 & 1,1 & 31 & 6,1 & 145 & 12 & 17 \\
\hline \multicolumn{14}{|l|}{ Milho } \\
\hline Folha & 1,9 & 2,9 & 3,3 & 26 & 17 & 5 & 2,6 & 1,3 & 27 & 8,2 & 131 & 27 & 14 \\
\hline Grão & 4,1 & 4,1 & 4,2 & 13 & 5 & 6 & 2,0 & 0,8 & 30 & 2,0 & 45 & 6 & 5 \\
\hline
\end{tabular}

${ }_{1}^{1} \mathrm{P}_{1}, \mathrm{P}_{2}$ e $\mathrm{P}_{3}$ : teor de fósforo nas doses de adubação de 250,500 e $1.000 \mathrm{~kg}^{-1} \mathrm{de}_{2} \mathrm{O}_{5}$, respectivamente.

2 IA: irrigação adequada; IR: irrigação restrita.

\section{CONCLUSÕES}

1. Quanto mais elevados os níveis de adubação fosfatada, maiores são as produtividades do feijão, com nível adequado de água.

2. A irrigação restrita promove reduções na produtividade do feijão, tendo menor efeito negativo no solo com maior disponibilidade de P.

3. O feijão apresenta uma resposta linear às doses de adubação fosfatada a lanço, aplicada antes do plantio, de até $1.000 \mathrm{~kg} \mathrm{ha}^{-1}$ de $\mathrm{P}_{2} \mathrm{O}_{5}$.

4. O milho mostra resposta significativa à adubação fosfatada.

5. O efeito residual da adubação fosfatada permite a obtenção de boas produtividades nos quatro cultivos de feijão e cinco cultivos de milho em rotação.

\section{REFERÊNCIAS}

BARBER, S.A. Influence of the plant root on ion movement in soil. In: CARSON, E.W. (Ed.). The plant roots and its environment. Charlottesville : University Press of Virginia, 1974. p.525-564.

BARBOSA FILHO, M.P.; SILVA, O.F. da. Aspectos agroeconômicos da calagem e da adubação nas culturas de arroz e feijão irrigados por aspersão. Pesquisa Agropecuária Brasileira, Brasília, v.29, n.11, p.16571667, nov. 1994.

BERGER, P.G.; VIEIRA, C.; CHAGAS, J.M.; CARDOSO, A.A. Resposta do feijoeiro (Phaseolus vulgaris
L.) à adubação nitrogenada e fosfatada. In: REUNIÃO NACIONAL DE PESQUISA DE FEIJÃO, 1., 1982, Goiânia. Anais. Goiânia : EmbrapaCNPAF, 1982. p.178-181.

CARVALHO, A.A. de; FAGERIA, N.K.; OLIVEIRA, I.P. de; KINJO, T. Resposta do feijoeiro à aplicação de fósforo em solos dos cerrados. Revista Brasileira de Ciência do Solo, Campinas, v.19, n.1, p.61-67, 1995.

EMBRAPA. Serviço Nacional de Levantamento e Conservação de Solos (Rio de Janeiro, RJ). Manual de métodos de análises de solo. Rio de Janeiro, 1979. Não paginado.

FRIZZONE, J.A.; CASSIANO SOBRINHO, F.; SÁ, M.E. de; BUZETTI, S. Efeito da irrigação e da adubação fosfatada sobre a produção de feijão (Phaseolus vulgaris L.). In: REUNIÃO NACIONAL DE PESQUISA DE FEIJÃO, 1., 1982, Goiânia. Anais. Goiânia : Embrapa-CNPAF, 1982. p.169-172.

GAHOONIA, T.S.; RAZA, S.; NIELSEN, N.E. Phosphorus depletion in the rhizosphere as influenced by soil moisture. Plant and Soil, Dordrecht, v.159, n.2, p.213-218, 1994.

HAGIN, J.; TUCKER, B. Fertilization of dryland and irrigated soils. Berlin : Springer, 1982. 188p.

IGNAZI, J.C. Influence of climatic conditions on the response to phosphate in experiment on field crops. Phosphorus in Agriculture, Paris, n.70, p.85-91, June 1977.

INFORZATO, R.; MYASAKA, S. Sistema radicular do feijoeiro em dois solos do Estado de São Paulo. Bragantia, Campinas, v.22, n.2, p.477-482, 1963. 
JAMES, D.W.; HANKS, R.J.; JURINAK, J.J. Modern irrigated soils. New York : J. Wiley, 1982. 235p.

MACKAY, A.D.; BARBER, S. Soil moisture effect on root growth and phosphorus uptake by corn. Agronomy Journal, Madison, v.77, n.4, p.519-523, 1985.

MATAR, A.E. Yields and response of cereal crops to phosphorus fertilization under changing rainfall conditions. Agronomy Journal, Madison, v.69, n.5, p.879-881, 1977.

MIRANDA, L.N. de; LOBATO, E. Tolerância de variedades de feijão ao alumínio e a baixa disponibilidade de fósforo no solo. Revista Brasileira de Ciência do Solo, Campinas, v.2, n.1, p.44-50, 1978.

MIRANDA, L.N. de; MIELNICZUK, J.; LOBATO, E. Calagem e adubação corretiva. In: SIMPÓSIO SOBRE O CERRADO, 5., 1979, Brasília. Cerrado: uso e manejo. Brasília : Editerra, 1980. p.523-578.

MODEL, N.S.; ANGHINONI, I. Resposta do milho a modos de aplicação de adubos e técnicas de preparo do solo. Revista Brasileira de Ciência do Solo, Campinas, v.16, n.1, p.55-59, 1992.

OLSEN, S.R.; WATANABE, F.S. Diffusive supply of phosphorus in relation to soil textural variations. Soil Science, Baltimore, v.110, n.5, p.318-327, 1970.
RAIJ, B. van. Fertilidade do solo e adubação. Piracicaba : Ceres/POTAFOS, 1991.343p.

ROSOLEM, C.A. Nutrição e adubação do feijoeiro. Piracicaba : Associação Brasileira para Pesquisa da Potassa e Fosfato, 1987. 93p. (Boletim Técnico, 1).

RUIZ, H.A.; BERNARDES, B.; NOVAIS, R.F.; ALVAREZ, V.H.; PEREIRA, P.A. Efeito do conteúdo de água sobre os níveis críticos de fósforo em dois latossolos. Revista Brasileira de Ciência do Solo, Campinas, v.12, n.1, p.43-48, 1988.

SILVEIRA, P.M. da; MOREIRA, J.A.A. Resposta do feijoeiro a doses de fósforo e lâminas de água de irrigação. Revista Brasileira de Ciência do Solo, Campinas, v.14, n.1, p.63-67, 1990.

SILVEIRA, P.M. da; STEINMETZ, S.; GUIMARÃES, C.M.; AIDAR, H.; CARVALHO, J.R.P. de. Lâminas de água e turnos de rega na cultura do feijoeiro de inverno. Pesquisa Agropecuária Brasileira, Brasília, v.19, n.2, p.219-223, fev. 1984.

STONE, L.F.; PEREIRA, A.L. Sucessão arroz-feijão irrigados por aspersão: efeitos do espaçamento entre linhas, adubação e cultivar na produtividade e nutrição do feijoeiro. Pesquisa Agropecuária Brasileira, Brasília, v.29, n.4, p.521-533, abr. 1994. 